\title{
AN OVERVIEW THE USE OF VITAMIN C FOR COVID-19 PATIENT
}

\author{
Ryka Marina Walanda ${ }^{a *}$, Tri Setyawati ${ }^{\mathrm{b}}$ \\ a ryykaa@gmail.com \\ ${ }^{a}$ Faculty of Medicine, Tadulako University, Indonesia \\ ${ }^{b}$ Faculty of Medicine, Tadulako University, Indonesia
}

\begin{abstract}
Coronavirus disease 2019 (COVID-19) as an emerging disease has not yet been accompanied by standardized treatment. One of the potential medicines used to treat COVID-19 cases is vitamin C, which can be used in COVID-19 therapy because it can boost the immune system and function as an antioxidant. Consuming vitamin $\mathrm{C}$ can increase the work of white blood cells, reduce tissue and cell damage, and minimize virus proliferation. Vitamin C insufficiency is thought to create an individual more helpless to illness. Meanwhile, someone suffering from a disease will have an increased need for vitamin $\mathrm{C}$ due to a high inflammatory and metabolic process. For Indonesians, the nutritional adequacy ratio (RDA) of vitamin C is $90 \mathrm{mg} /$ day for men over 15 years of age and $75 \mathrm{mg}$ /day for women over 15 years of age. This sufficiency can be met from food, such as vegetables and fruit. However, if you cannot fulfill it from food alone, you can add supplements. Several clinical trials regarding the administration of vitamin C in patients with severe Covid-19 sepsis and acute respiratory distress syndrome (ARDS) and complications of sepsis have shown results as empirical therapy
\end{abstract}

Published by IJRP.ORG. Selection and/or peer-review under responsibility of International Journal of Research Publications (IJRP.ORG)

\section{Introduction}

Coronavirus Disease 2019 (COVID-19) is a respiratory infection caused by a coronavirus and was first discovered in Wuhan, China, in December 2019. Most COVID-19 patients show mild symptoms or without complications (Kunal et al., 2020), but around 14\% of patients have symptoms weight requiring hospitalization and oxygen support, and 5\% of patients requiring care in the intensive care unit (ICU) (Chavarría et al., 2021). The World Health Organization (WHO), on March 11, 2020, has declared COVID-19 a pandemic (Cucinotta \& Vanelli, 2020). This condition has become one of the leading health focuses for many countries globally, including Indonesia. Of course, we all want to do our best to prevent getting COVID-19 and get well soon if infected.

The latest data in Indonesia (as of August 14, 2020) recorded 132,816 confirmed cases of coronavirus infection, of which nearly 66 percent have recovered, 4.5 percent died, and the rest are still undergoing 
treatment (Aungsuroch, Juanamasta, \& Gunawan, 2020). So, how can we deal with the symptoms of the coronavirus? Some of the symptoms of the coronavirus that are often disseminated are symptoms of respiratory tract infections (cough, runny nose, shortness of breath) and fever. Data from the Task Force for the Acceleration of Handling COVID-19, the symptoms that often appear in people exposed to covid-19 are as follows: from the most common in positive confirmed cases: Cough (70.3\%), History of fever (46.7\%), or fever (38.5\%), shortness of breath (33.9\%), fatigue (29.6\%), runny nose (25.7\%), Sore throat $(24.7 \%)$, headache $(21.8 \%)$, nausea (18.8\%), muscle cramps (15\%), chills $(9 \%)$, abdominal pain $(7.4 \%)$, diarrhea ( 7.2\%) ("Akurasi Data Kunci Kebijakan Efektif," n.d.). In severe cases, COVID-19 can be accompanied by acute respiratory distress syndrome (ARDS), sepsis and septic shock, multi-organ failure, including acute kidney injury (AKI) and cardiac injury. In COVID-19 patients, the total number of B cells, T cells, and natural killer cells (NK cells) decreased significantly, and their use was more pronounced in severe cases than in non-severe instances (Gabarre et al., 2020).

In Indonesia, several guidelines for handling COVID-19 also recommend giving vitamin C. Apart from food intake; vitamin $\mathrm{C}$ can be found from supplements. One of the vitamin $\mathrm{C}$ supplements that you can take is Joss C-1000. This supplement contains $1,000 \mathrm{mg}$ of vitamin $\mathrm{C}$, with additives in aspartame, acesulfame-K, sodium bicarbonate, citric acid, and lime flavor. Besides increasing endurance, the consumption of $1,000 \mathrm{mg}$ of vitamin $\mathrm{C}$ can also increase iron absorption in the body. How to consume it, dissolveone1 sachet of Joss C$1000 \mathrm{in} 300 \mathrm{ml}$ of cold water (stir if necessary) (Mustofa, n.d.).

Although there is a variety of promising evidence to improve the condition of COVID-19 patients who are given vitamin $\mathrm{C}$, however, vitamin $\mathrm{C}$ has not been proven to prevent COVID-19. So, even though vitamin $\mathrm{C}$ has benefits in supporting immunity, it still needs to be accompanied by health protocols to prevent coronavirus infection. For those who have symptoms or have been confirmed positive for the coronavirus, it does not hurt to take vitamin $\mathrm{C}$ according to the guidelines issued for the Indonesian people. Given that vitamin $\mathrm{C}$ is a type of vitamin that is often associated with the immune system, it is often discussed during this pandemic.

An analysis of six studies found that administering high doses of vitamin $\mathrm{C}$ reduced the duration of ICU stay $(8.6 \%)$ and period of use of a ventilator or breath aid (18.2\%) (Hemilä \& Chalker, 2019). In 2020 a consensus was issued for handling COVID-19 by the Shanghai medical association, which recommended giving vitamin $C$ to patients with coronavirus infection (Cheng, Kogan, \& Davis, 2020). In Indonesia, some guidelines for handling COVID-19 recommend giving vitamin $\mathrm{C}$ to confirmed but asymptomatic patients. It is recommended that you take $3-4 \times 500 \mathrm{mg}$ of non-acidic vitamin $\mathrm{C}$ tablets per day for 14 days or $2 \times 500 \mathrm{mg}$ vitamin $\mathrm{C}$ tablets per day for 30 days or multivitamins containing vitamin C 1-2 times per day for 30 days (COVID-19 Management Protocol) (Buku Saku Protokol Tatalaksana COVID-19 di Indonesia, n.d.). As for people under supervision and health workers, it is consuming 500-1000 $\mathrm{mg}$ of vitamin $\mathrm{C}$ per day is recommended. Person with mild symptoms is advised to consume $1000 \mathrm{mg}$ of vitamin C per day. Those with severe and critical symptoms are reported to be given high doses of vitamin C, generally by IV (Practical Guidelines for Nutrition Management of COVID-19) (Perhimpunan Dokter Spesialis Gizi Klinik Indonesia, n.d.). An overview of the administration of vitamin $\mathrm{C}$ and its dosage will be presented in this paper.

\section{Literature Review of Vitamin C}

Vitamin $\mathrm{C}$ is known to have various positive benefits for the body, such as supporting the immune system, preventing disease, and increasing the antioxidant content. Vitamin $\mathrm{C}$ or ascorbic acid is a water-soluble sixcarbon compound. The chemical name of ascorbic acid (2R) -2 - [(1S) -1,2- dihydroxyethyl] -3,4-dihydroxy$2 \mathrm{H}$-furan-5-one PubChem. The main forms of ascorbic acid are L-ascorbic and dehydroascorbic acid (Chen et al., 2021). Vitamin C is a vitamin synthesized from glucose in the liver from all mammals, except humans. Humans do not have the enzyme gluconolactone oxidase, which is very important for synthesizing vitamin C 
precursors, namely 2- keto-1-gluconolactone, so humans cannot synthesize vitamin C in their bodies (Drouin, Godin, \& Page, 2011).

Vitamin $C$ is the most volatile of all vitamins and is easily damaged during processing and storage. The rate of damage increases due to metalwork, especially copper and iron and enzyme action. Enzymes containing copper or iron in their prosthetic groups are efficient catalysts for the breakdown of ascorbic acid. The foremost vital chemicals in this gather are corrosive ascorbic oxidase, phenolase, cytochrome oxidase, and peroxidase. Only ascorbic acid oxidase is involved in the direct reaction between enzymes, substrates, and molecular oxygen. Other enzymes oxidize vitamins indirectly. Phenolases catalyze the oxidation of mono- and dihydroxy phenols to quinones. Quinone reacts directly with ascorbic acid.<smiles>O=C1O[C@H]([C@@H](O)CO)C(O)=C1O</smiles>

Vitamin C (Milanesio, Bianchi, Ugliengo, Roetti, \& Viterbo, 2004)

Cytochrome oxidase oxidizes cytochrome and reacts with L-ascorbic acid. Peroxidases combine with phenolic compounds using hydrogen peroxide to carry out oxidation (Fecht-Christoffers, Führs, Braun, \& Horst, 2006). Vitamin $\mathrm{C}$ is stable in dry conditions, but in the form of a solution, it is easily oxidized to dehydroascorbic acid, especially by the influence of oxygen, light, and $\mathrm{pH}$ (vitamin $\mathrm{C}$ solution is most stable at $\mathrm{pH}$ below 4). Storage of vitamin $\mathrm{C}$ in a tightly closed container and protected from light. Vitamin $\mathrm{C}$ cannot blend with antacids, overwhelming metal particles, particularly iron(III) and copper(II), oxidizing compounds, methenamine, phenylephrine hydrochloride, pyrilamine maleate, salicylamide, sodium nitrite, sodium salicylate, and theobromine salicylate (Liu, Cao, \& Jiang, 2015). When exposed to light, Vitamin C is exposed to heating and in an alkaline environment can be oxidized to L-dehydroascorbic acid. Furthermore, L-dehydroascorbic acid is oxidized further to form 2,3 diketogulonic acid, and then it can become oxalic acid and 1-threonic acid. The reaction of vitamin $\mathrm{C}$ to $\mathrm{L}$-dehydroascorbic acid is reversible, while the other responses are not (Kall, 2003).

The benefits of Vitamin $\mathrm{C}$ are indicated for the prevention and treatment of scurvy and the common cold. Also, vitamin $\mathrm{C}$ is used as a medicine against diseases with nothing to do with vitamin $\mathrm{C}$ deficiency, but the dose given is the most significant. Sometimes, it causes excess C and diarrheal (Tolonen, 1996). In doing activities, vitamin $\mathrm{C}$ is also needed, especially for exercising, studying, etc. Activities such as exercise usually require vitamin $\mathrm{C}$, but the amount necessary for training is the same as daily needs, $75 \mathrm{mg}$. Excessive consumption of vitamin $\mathrm{C}$ in people who exercise is not recommended because the rest of the vitamin $\mathrm{C}$ consumed will be excreted through sweat and urine (Marcus, 2013). Vitamin C, as an antioxidant, is an electron donor and a reducing agent. They are called antioxidants because by donating electrons, this vitamin prevents other compounds from being oxidized. However, vitamin $\mathrm{C}$ will be oxidized in the antioxidant process, resulting in dehydroascorbic acid (Frikke-Schmidt, Tveden-Nyborg, \& Lykkesfeldt, 2016). The ascorbyl radical and dehydroascorbic corrosive can be decreased back to ascorbic corrosive with the assistance of the protein 4-hydroxyphenylpyruvate dioxygenase. However, in the human body, the reduction occurs only partially, so that the oxidized ascorbic acid is not entirely back (Lykkesfeldt, Viscovich, \& Poulsen, 2003).

Vitamin $\mathrm{C}$ is also readily oxidized reversibly to form dihydroascorbic acid and loses two hydrogen atoms. Vitamin $\mathrm{C}$ has a structure similar to monosaccharides but contains an enadiol group. Naturally, the form of vitamin $\mathrm{C}$ is the L-isomer. Activity is greater than that of the $\mathrm{D}$-isomeric state. The action of vitamin $\mathrm{C}$ in the D isomer is only $10 \%$ of the L-isomer activity (Gentili \& Caretti, 2013). Vitamin C can be an antioxidant for 
lipids, proteins, and DNA by (1) lipids, such as Low-Density Lipoprotein (LDL), which will react with oxygen to become lipid peroxide. The next one will produce lipid hydroperoxides, which will have free radicals. Ascorbic acid will react with oxygen so that there is no interaction between lipids and oxygen and will prevent the formation of lipid hydroperoxides. (2) For protein, vitamin C prevents the reaction of oxygen and peptide-forming amino acids or oxygen and protein-forming peptides. (3) For DNA, DNA reactions with oxygen will cause DNA damage which eventually causes mutations (García-Rodríguez, Gordillo-García, \& Altamirano-Lozano, 2017). As a source of vitamin C, generally, the mind is focused on oranges. There are other fruits and vegetables that offer more vitamin $C$ than oranges. The following table shows the vitamin $C$ content of some plants, foods (What Are the Best Food for Vitamin C?, n.d.):

\begin{tabular}{lclc}
\hline Source & Amount(mg/100g) & Source & Amount (mg/100g) \\
\hline Kakadu plum & 3100 & Baobab & 400 \\
Camus & 2800 & Blackcurrant & 200 \\
Rosehip & 2000 & Red pepper & 190 \\
Acerola & 1600 & Parsley & 130 \\
Sea buckthorn & 695 & Guava & 100 \\
Jujube & 500 & Kiwifruit & 90 \\
Indian gooseberry & 445 & Broccoli & 90 \\
Loganberry & 80 & Banana & 9 \\
Redcurrant & 80 & Carrot & 9 \\
Brussels sprouts & 80 & Avocado & 8 \\
Wolfberry (Goji) & 73 & Crab apple & 8 \\
Lychee & 70 & Persimmon - fresh & 7 \\
Cloudberry & 60 & Cherry & 7 \\
Elderberry & 60 & Peach & 7 \\
Persimmon & 60 & Apple & 6 \\
Grape & 10 & Asparagus & 6 \\
Apricot & 10 & Beetroot & 5 \\
Plum & 10 & Chokecherry & 5 \\
Watermelon & 10 & Pear & 4 \\
Lettuce & 4 & Fig & 2 \\
Cucumber & 3 & Bilberry & 1 \\
Eggplant & 2 & Horned melon & Medlar \\
Raisin & 2 & & 0.5 \\
\hline
\end{tabular}

At doses higher than generally used for outpatients, Vitamin $\mathrm{C}$ has been shown to reduce mortality in sepsis and has positive clinical outcomes in patients suffering from viral infections (Kuhn, Meissner, Mayes, \& Bartels, 2018). The exact mechanism of vitamin C beneficial effect is unclear; however, it is known that vitamin $\mathrm{C}$ is a potent antioxidant with immunomodulatory properties and is significantly concentrated in critical immune cells. It supports lymphocyte cell function and proliferation and increases the capacity of phagocytes and oxidative killing by neutrophils (Carr \& Maggini, 2017)

Research has demonstrated a possible clinical benefit in patients with other viruses, including shingles, varicella-zoster, and influenza, through unclear antiviral mechanisms, helps prevent the common cold (Gershon et al., 2015). Vitamin C has also reduced the duration and severity of cold symptoms in supplementation trials (Bucher \& White, 2016).

\section{Vitamin C for Covid-19 Patients}

The added antioxidant properties make it very beneficial for vitamin $\mathrm{C}$ to clean up harmful reactive oxygen species (ROS) used by immune cells to inactivate viruses and cause inflammation and harm human cells. ROS is essential in patients with respiratory disease because it causes damage to the lungs (Valavanidis, 
Vlachogianni, Fiotakis, \& Loridas, 2013). This can contribute to an inflammatory storm affecting patients with severe COVID-19. Having powerful antioxidants to clear ROS may be of benefit in symptomatic COVID-19 patients.

Besides, vitamin $\mathrm{C}$ has shown some benefit in septic patients and, although it is still being investigated, may prove beneficial in severe COVID-19 patients (Hoang, Shaw, Fang, \& Han, 2020a). A study conducted for septic patients with acute respiratory distress syndrome (ARDS) $(n=167)$ showed a lower 28-day mortality rate and an increased number of ICU-free and hospital-free days in patients randomized to intravenous (IV) vitamins C (50 mg/kg every 6 hours) compared with placebo (Kashiouris et al., 2020). Since ARDS is a major complication of severe COVID-19, vitamin C may prove beneficial. These are secondary outcomes, and consistent results in studies where they are evaluated as primary products are needed to confirm the findings.

One noted precaution from previous vitamin $\mathrm{C}$ trials was that it could alter the results of the on-site glucose tests, causing blood glucose levels to become very high, resulting in an excessively high insulin dose (Dakhale, Chaudhari, \& Shrivastava, 2011). One solution to this problem could be to monitor serum blood glucose levels rather than care levels in hospitalized patients receiving high doses of vitamin C. Other side effects that may be noted include hypernatremia, oxalate nephropathy, and hemolysis in G6PD deficient patients, but these are rare (Afra, Nampoothiri, Razmi T, \& Hafi, 2020).

Among the various functions of vitamin $\mathrm{C}$, tasks relevant to critical conditions in the case of COVID-19 include the role of vitamin $\mathrm{C}$ in increasing the immune system and its position as an antioxidant. Vitamin $\mathrm{C}$ can increase chemotaxis and neutrophil phagocytosis, thereby increasing microbial clearance. Also, vitamin C enhances differentiation, proliferation and modulates the function of $\mathrm{T}$ cells, B cells, and natural killer cells. Vitamin $\mathrm{C}$ is also capable of inducing the production of antibodies in humans ("Akurasi Data Kunci Kebijakan Efektif," n.d.; Gabarre et al., 2020; Mustofa, n.d.). Deficiency of vitamin C can lead to impaired immunity and increased susceptibility to infections. In COVID-19, when the protective immune response is disrupted, the virus will propagate and cause tissue damage. The harmed cells initiate aggravation within the lung which is generally intervened by proinflammatory macrophages and granulocytes. In sepsis, there's oxidative stress and an abundance of proinflammatory go-betweens. This may lead to expanded endothelial porousness coming about in microcirculation clutters. Vitamin $\mathrm{C}$ can restrain endothelial harm caused by these ROS (receptive oxygen species). Vitamin C utilized intravenously in tall dosages can work pleiotropically as a prooxidant, making a difference increment the clearance of alveolar liquid and as an antioxidant that makes strides epithelial work (Gabarre et al., 2020; Hemilä \& Chalker, 2019; Cheng et al., 2020; Buku Saku Protokol Tatalaksana COVID-19 di Indonesia, n.d.).

One of the early studies regarding the positive effect of vitamin $\mathrm{C}$ in sepsis was conducted (Surani \& Sharma, 2019). In this before-after study design, it was concluded that giving vitamin C, together with hydrocortisone and thiamine, could prevent the progression of organ dysfunction and reduce mortality in patients with severe sepsis and septic shock. However, the relatively small sample size can limit the generalizability of the study results (Litwak, Cho, Nguyen, Moussavi, \& Bushell, 2019).

A few cases report in the interim specify oxalate nephropathy in patients who got tall measurements of vitamin C. Oxalate nephropathy occurs due to the accumulation of calcium oxalate. This could be due to the high consumption of oxalate precursors, one of which is vitamin C. Another chance to be mindful of when utilizing tall measurements of vitamin $\mathrm{C}$ in the event of hemolysis in patients with G6PD lack and press overburden in patients with hemochromatosis (Drouin et al., 2011).

A meta-analysis and systematic review regarding the use of vitamin $\mathrm{C}$ in critically ill patients was carried out. The study includes five randomized controlled trials (RCT) studies and one retrospective study with a total sample size of 142 samples. The study found that compared with controls, intravenous vitamin C use was associated with decreased vasopressor requirements and reduced duration of mechanical ventilation, but 
there was no difference in mortality. It was concluded that intravenous vitamin $\mathrm{C}$ has vasopressor sparing effects and reduces the need for mechanical ventilation in critically ill patients without affecting mortality (Kall, 2003; Tolonen, 1996).The paper provides information to help patients with the Covid-19 coronavirus by relieving their symptoms. Other findings from the study included: Many patients infected with the Covid19 coronavirus had so badly low vitamin $\mathrm{C}$ levels that they developed scurvy; Controlled trials have found high doses of vitamin $\mathrm{C}$ to be more effective than steroids; Vitamin $\mathrm{C}$ levels in patients in intensive care predict their chances of survival; Humans are one of those living things that cannot make their vitamin $\mathrm{C}$ in the body.

The conclusions from the results of 100 studies, including the gold standard RCT (Randomized Controlled Trial), show that vitamin $\mathrm{C}$ can cut the death rate from coronavirus in intensive care units by 68 percent (Carr, 2019). Once you have a severe crown infection contamination, the body employments vitamin $\mathrm{C}$ at a much speedier rate to bolster the resistance framework. The study also pointed out that many animals cannot produce vitamin $\mathrm{C}$ on their own like humans, such as primates, guinea pigs, and bats. These animals are also at risk of being infected with the Covid-19 coronavirus.

This finding is supported by research showing that most Covid-19 coronavirus patients who enter the ICU have deficient levels of vitamin C (Simonson, 2020). Low levels of vitamin C among Covid-19 coronavirus patients were frequently detected, or for this reason, coronavirus infection causes scurvy in people who are deficient in vitamin C. Role of food and the life chances of patients with the Covid-19 coronavirus by looking at the levels of vitamin $\mathrm{C}$ in their bodies. Patients need high doses of vitamin $\mathrm{C}$ to treat scurvy. Vitamin $\mathrm{C}$ is also necessary to reduce the dangerous inflammation that develops due to the Covid-19 coronavirus. Combining vitamin $\mathrm{C}$ with steroids and anticoagulant drugs can also reduce the death rate of critically ill Covid-19 coronavirus patients to less than 5 percent (Thirumdas, Kothakota, Pandiselvam, Bahrami, \& Barba, 2021).

\section{Vitamin C Dosage for Covid-19 Patients}

Several studies are being conducted to evaluate the effects of vitamin C in the treatment of COVID-19. One phase 2 study evaluated how high doses of IV vitamin C (12 g infused for 4 hours every 12 hours for seven days) treatment affected severe COVID-19-related pneumonia (Hoang et al., 2020a).

A phase 3 trial in Canada studied the effects of vitamin C (50 mg/kg IV every 6 hours for four days) on organ dysfunction and mortality in COVID-19 (Milani, Macchi, \& Guz-Mark, 2021). Results for these two studies determine the role of vitamin $\mathrm{C}$ in the treatment of COVID-19.

One clinical trial assessed the safety of using intravenous vitamin $\mathrm{C}$ in patients with severe sepsis. In this clinical trial, research subjects were divided into three groups: the group that received a placebo, vitamin $\mathrm{C}$ at a dose of $50 \mathrm{mg} / \mathrm{kg} / 24$ hours, and vitamin $\mathrm{C}$ at an amount of $200 \mathrm{mg} / \mathrm{kg} / 24$ hours (Hoang et al., 2020a). It was found that no side effects occurred in patients who received intravenous vitamin $\mathrm{C}$, and it was concluded that intravenous vitamin $\mathrm{C}$ administration was safe and tolerated (Hoang et al., 2020a).

A meta-analysis involving 12 studies with 1766 patients found that vitamin $\mathrm{C}$ administration could shorten the length of stay in the ICU. A meta-analysis of 6 studies found that vitamin C can reduce the duration of mechanical ventilation. Different results were obtained in a meta-analysis of 44 clinical trials also conducted. From these studies, it was found that the administration of vitamin $\mathrm{C}$ did not significantly affect the duration of stay in the ICU or hospital. (Marcus, 2013; Frikke-Schmidt et al., 2016).

Systematic review and meta-analysis involved 4 RCTs and two retrospective studies (Wang, Lin, Lin, \& Lin, 2019). The meta-analysis found that high doses of vitamin $C$ ( $>50 \mathrm{mg} / \mathrm{kg} / \mathrm{day}$ ) significantly reduced the mortality rate for patients with severe sepsis. However, the addition of high doses of vitamin $\mathrm{C}$ to the treatment of severe sepsis did not reduce the length of stay in the ICU. These results are supported by the 
results of a meta-analysis which concluded that there is a positive correlation between giving vitamin $\mathrm{C}$ in cases of sepsis with better survival and the use of the shorter duration of vasopressors (Cheng et al., 2020; Lykkesfeldt et al., 2003).

There were no clinical trial results related to the use of vitamin $\mathrm{C}$ in COVID-19 cases. The current use of vitamin $\mathrm{C}$ is an empirical therapy based on the experience of clinicians in China who provide intravenous vitamin $\mathrm{C}$ with doses ranging from $50-200 \mathrm{mg} / \mathrm{kg}$ Body Weight according to the severity of the disease. Also, vitamin $\mathrm{C}$ administration has been shown to prevent acute respiratory infections in some special populations such as marathons, ski athletes, and military personnel, but not in the general population. From the research, it was found that regular supplementation with a minimum dose of $200 \mathrm{mg} /$ day can reduce the duration of ARI by $8 \%$ in adults (Aungsuroch et al., 2020; Gentili \& Caretti, 2013).

Guidelines issued by the Indonesian Lung Doctors Association (PDPI) recommend using vitamin C for the treatment of COVID-19 pneumonia. For COVID-19 pneumonia without symptoms and mild symptoms, oral vitamin $\mathrm{C}$ is given at a dose of 100-200 mg 3 times/day. For moderate and severe symptomatic COVID-19 pneumonia, intravenous vitamin C is recommended ("Have A Double Protection with IV Vitamin C Therapy During New Normal," n.d.). The Association of Indonesian Internal Medicine Specialists (PAPDI), in its website, recommends using vitamin C at a dose of 200-400 mg/8 hours intravenously for patients with moderate and severe symptoms of COVID-19 ("Have A Double Protection with IV Vitamin C Therapy During New Normal," n.d.).

Clinical trials concerning the utilize of intravenous vitamin C in COVID-19 cases have been carried out in Hubei, China. Within the clinical trial, the intravenous measurements of vitamin $\mathrm{C}$ were 12 grams given twice every day for seven days and compared to a fake treatment mixture pump with a speed of $12 \mathrm{~mL} / \mathrm{h}$ (Liu, Zhu, Zhang, Li, \& Peng, 2020).

Various high-dose intravenous VC infusions (e.g., $200 \mathrm{mg} / \mathrm{kg}$ body weight/day, divided into four doses) shortened the intensive care unit (ICU) stay by 7.8\%. (Hemilä \& Chalker, 2019). 1 High-dose intravenous VC has also been successfully used to treat 50 moderate to severe COVID-19 patients in China. The doses used varied between $10 \mathrm{~g}$ and $20 \mathrm{~g}$ per day, given throughout 8-10 h. High-dose vitamin $\mathrm{C}$ has been clinically used for several decades. A recent NIH expert panel document clearly states that this regimen $(1.5 \mathrm{~g} / \mathrm{kg}$ body weight) is safe and without significant adverse events ("High-Dose Vitamin C (PDQ®)-Health Professional Version," n.d.).

The following is a list of vitamin $\mathrm{C}$ recommendations for Covid-19; for patients without symptoms are non-acidic vitamin $C$ tablets $500 \mathrm{mg} / 6-8$ hours orally (for 14 days), or vitamin C lozenges $500 \mathrm{mg} / 12$ hours orally (for 30 days), or multivitamins containing 1-2 tablets of vitamin C/24 hours (for 30 days). For patients with mild symptoms, vitamin $\mathrm{C}$, with options: $500 \mathrm{mg} / 6-8$ hour oral non-acidic vitamin $\mathrm{C}$ tablets (for 14 days), or $500 \mathrm{mg} / 12$ hour oral vitamin $\mathrm{C}$ lozenges (for 30 days), or a multivitamin that is contains Vitamin $\mathrm{C}$ 1-2 tablets/24 hours (for 30 days) (Rondanelli et al., 2018). Meanwhile, giving vitamin $\mathrm{C}$ to sufferers of Covid-19 in a degree is done intravenously because moderate-grade patients generally already have pneumonia and are hospitalized (Hoang et al., 2020b). In Covid-19 patients, an extreme or basic degree implies that they as of now require clinic care. Giving vitamins is done intravenously concurring to a doctor's medicine. In expansion to taking vitamins, take solutions that your specialist has endorsed. Specialists will endorse drugs in agreement with the Covid-19 Administration Rules that have been conveyed to specialists all through Indonesia.

\section{Conclusion}

Hypothetically, there are different benefits of utilizing vitamin $\mathrm{C}$ that is significant to COVID-19 cases. A few positive comes about from the employ of vitamin $\mathrm{C}$ in patients of actual ailment and sepsis in expansion, 
from a few meta-analyses. Be that as it may, there are no clinical trials or meta-analyses concerning the utilization of vitamin C in COVID-19 cases. The utilization of vitamin C in patients of COVID-19 is an experimental treatment based on the encounter of clinicians in China. It must consider the risk-benefit proportion, particularly concerning the chance of potential side impacts. PDPI prescribes the utilize of vitamin $\mathrm{C}$ for the treatment of COVID-19 pneumonia. For mellow COVID-19 pneumonia, verbal vitamin $\mathrm{C}$ is given at a dosage of $3 \times 100 \mathrm{mg}$. For severe COVID-19 pneumonia, given intravenous vitamin $\mathrm{C}$ at measurements of $1 \times 400 \mathrm{mg}$. In the interim, severe COVID-19 pneumonia with complications is treated with intravenous vitamin $C$ at a size of $1 \times 200 \mathrm{mg}$. Organization of vitamin $\mathrm{C}$ is generally secure, but its benefits within the case of COVID-19 are required to set up firm recommendations regarding the utilization of vitamin $\mathrm{C}$ and zinc within the treatment of COVID-19 positive patients, their past victory in infections and other sepsis, ease of getting to, generally low costs, and their solid security profile makes them alluring alternatives as adjunctive treatments.

\section{Acknowledgements}

The support from colleagues in the Faculty of Medicine Tadulako University and Kabelota Hospital are highly appreciated.

\section{References}

Afra, T. P., Nampoothiri, R. V., Razmi T, M., \& Hafi, N. A. B. (2020). Linking hydroxychloroquine to hemolysis in a 'suspected' glucose-6-phosphate dehydrogenase deficient patient with COVID-19 infection - a critical appraisal. European Journal of Internal Medicine, 80, 101-102.

Akurasi Data Kunci Kebijakan Efektif. (n.d.). Retrieved from Covid19.go.id website: https://covid19.go.id/berita/satgas-covid-19akurasi-data-kunci-kebijakan-efektif

Aungsuroch, Y., Juanamasta, I. G., \& Gunawan, J. (2020). Experiences of Patients with Coronavirus in the COVID-19 Pandemic Era in Indonesia. Asian Journal for Public Opinion Research, 8(3), 377-392.

Bucher, A., \& White, N. (2016). Vitamin C in the Prevention and Treatment of the Common Cold. American Journal of Lifestyle Medicine, 10(3), 181-183.

Buku Saku $\quad$ Protokol Tatalaksana COVID-19 di Indonesia. (n.d.). Retrieved from https://www.kemkes.go.id/article/view/20092400001/buku-saku-protolol-tatalaksana-covid-19-di-indonesia.html

C Loss in Vertebrates. Current Genomics, 12(5), 371-378.

Carr, A. C. (2019). Vitamin C administration in the critically ill: A summary of recent meta-analyses. Critical Care, 23(1), 265.

Carr, A., \& Maggini, S. (2017). Vitamin C and Immune Function. Nutrients, 9(11), 1211.

Chavarría, A. P., Vázquez, R. R. V., Cherit, J. G. D., Bello, H. H., Suastegui, H. C., Moreno-Castañeda, L.,Soto, M. E. (2021). Antioxidants and pentoxifylline as coadjuvant measures to standard therapy to improve prognosis of patients with pneumonia by COVID-19. Computational and Structural Biotechnology Journal, 19, 1379-1390.

Chen, L., Wang, W., Zhang, J., Cui, H., Ni, D., \& Jiang, H. (2021). Dual effects of ascorbic acid on the stability of EGCG by the oxidation product dehydroascorbic acid promoting the oxidation and inhibiting the hydrolysis pathway. Food Chemistry, 337, 127639.

Cheng, R. Z., Kogan, M., \& Davis, D. (2020). Ascorbate as Prophylaxis and Therapy for COVID-19-Update From Shanghai and U.S Medical Institutions. Global Advances in Health and Medicine, 9, 216495612093476.

Cucinotta, D., \& Vanelli, M. (2020). WHO Declares COVID-19 a Pandemic. Acta Bio Medica Atenei Parmensis, 91(1), 157-160.

Dakhale, G. N., Chaudhari, H. V., \& Shrivastava, M. (2011). Supplementation of Vitamin C Reduces Blood Glucose and Improves Glycosylated Hemoglobin in Type 2 Diabetes Mellitus: A Randomized, Double-Blind Study. Advances in Pharmacological Sciences, 2011, 1-5.

Fecht-Christoffers, M. M., Führs, H., Braun, H.-P., \& Horst, W. J. (2006). The Role of Hydrogen Peroxide-Producing and Hydrogen Peroxide-Consuming Peroxidases in the Leaf Apoplast of Cowpea in Manganese Tolerance. Plant Physiology, 140(4), 1451-1463.

Frikke-Schmidt, H., Tveden-Nyborg, P., \& Lykkesfeldt, J. (2016). L-dehydroascorbic acid can substitute 1-ascorbic acid as dietary vitamin C source in guinea pigs. Redox Biology, 7, 8-13.

Gabarre, P., Dumas, G., Dupont, T., Darmon, M., Azoulay, E., \& Zafrani, L. (2020). Acute kidney injury in critically ill patients with COVID-19. Intensive Care Medicine, 46(7), 1339-1348. 
García-Rodríguez, M. del C., Gordillo-García, A., \& Altamirano-Lozano, M. (2017). The Role of Vitamin C in the Protection and Modulation of Genotoxic Damage Induced by Metals Associated with Oxidative Stress. In A. H. Hamza (Ed.), Vitamin C. InTech.

Gentili, A., \& Caretti, F. (2013). Analysis of Vitamins by Liquid Chromatography. In Liquid Chromatography (pp. 477-517). Elsevier.

Gershon, A. A., Breuer, J., Cohen, J. I., Cohrs, R. J., Gershon, M. D., Gilden, D., Yamanishi, K. (2015). Varicella zoster virus infection. Nature Reviews Disease Primers, 1(1), 15016.

Have A Double Protection with IV Vitamin C Therapy During New Normal. (n.d.). Retrieved from Primeplusmed website: https://www.primeplusmed.com/id/iv-vitamin-therapy/

Hemilä, H., \& Chalker, E. (2019). Vitamin C Can Shorten the Length of Stay in the ICU: A Meta-Analysis. Nutrients, 11(4), 708.

High-dose vitamin C (PDQ®)-Health professional version. (n.d.). National Cancer Institute. Retrieved from https://www.cancer.gov/about-cancer/treatment/cam/hp/vitamin-c-pdq

Hoang, B. X., Shaw, G., Fang, W., \& Han, B. (2020a). Possible application of high-dose vitamin C in the prevention and therapy of coronavirus infection. Journal of Global Antimicrobial Resistance, 23, 256-262.

Holford, P., Carr, A. C., Jovic, T. H., Ali, S. R., Whitaker, I. S., Marik, P. E., \& Smith, A. D. (2020). Vitamin C-An Adjunctive Therapy for Respiratory Infection, Sepsis and COVID-19. Nutrients, 12(12), 3760.

Kall, M. A. (2003). ASCORBIC ACID I Properties and Determination. In Encyclopedia of Food Sciences and Nutrition (pp. 316-324). Elsevier.

Kashiouris, M. G., L'Heureux, M., Cable, C. A., Fisher, B. J., Leichtle, S. W., \& Fowler, A. A. (2020). The Emerging Role of Vitamin C as a Treatment for Sepsis. Nutrients, 12(2), 292.

Kuhn, S.-O., Meissner, K., Mayes, L. M., \& Bartels, K. (2018). Vitamin C in sepsis. Current Opinion in Anaesthesiology, 31(1), 55-60.

Kunal, S., Sharma, S. M., Sharma, S. K., Gautam, D., Bhatia, H., Mahla, H.,Bhandari, S. (2020). Cardiovascular complications and its impact on outcomes in COVID-19. Indian Heart Journal, 72(6), 593-598.

Litwak, J., Cho, N., Nguyen, H., Moussavi, K., \& Bushell, T. (2019). Vitamin C, Hydrocortisone, and Thiamine for the Treatment of Severe Sepsis and Septic Shock: A Retrospective Analysis of Real-World Application. Journal of Clinical Medicine, 8(4), 478.

Liu, F., Zhu, Y., Zhang, J., Li, Y., \& Peng, Z. (2020). Intravenous high-dose vitamin C for the treatment of severe COVID-19: Study protocol for a multicentre randomised controlled trial. BMJ Open, 10(7), e039519.

Liu, H., Cao, J., \& Jiang, W. (2015). Evaluation and comparison of vitamin C, phenolic compounds, antioxidant properties and metal chelating activity of pulp and peel from selected peach cultivars. LWT - Food Science and Technology, 63(2), 1042-1048.

Lykkesfeldt, J., Viscovich, M., \& Poulsen, H. E. (2003). Ascorbic acid recycling in human erythrocytes is induced by smoking in vivo. Free Radical Biology and Medicine, 35(11), 1439-1447.

Marcus, J. B. (2013). Vitamin and Mineral Basics: The ABCs of Healthy Foods and Beverages, Including Phytonutrients and Functional Foods. In Culinary Nutrition (pp. 279-331). Elsevier.

Milanesio, M., Bianchi, R., Ugliengo, P., Roetti, C., \& Viterbo, D. (2004). CCDC 245103: Experimental Crystal Structure Determination [CIF]. Cambridge Crystallographic Data Centre.

Milani, G. P., Macchi, M., \& Guz-Mark, A. (2021). Vitamin C in the Treatment of COVID-19. Nutrients, $13(4), 1172$.

Mustofa, A.. (n.d.). Bergerak Bersama Melawan Covid-19 dengan Konsumsi Joss C $1000 . \quad$ Retrieved from https://radarbali.jawapos.com/read/2020/12/10/229485/bergerak-bersama-melawan-covid-19-dengan-konsumsi-joss-c-1000

Perhimpunan Dokter SPesialis Gizi Klinik Indonesia. (n.d.). Panduan Praktis Penatalaksanaan Nutrisi COVID-19. Retrieved from https://covid19.go.id/edukasi/tenaga-kesehatan/panduan-praktis-penatalaksanaan-nutrisi-covid-19

Rondanelli, M., Miccono, A., Lamburghini, S., Avanzato, I., Riva, A., Allegrini, P.Perna, S. (2018). Self-Care for Common Colds: The Pivotal Role of Vitamin D, Vitamin C, Zinc, and Echinacea in Three Main Immune Interactive Clusters (Physical Barriers, Innate and Adaptive Immunity) Involved during an Episode of Common Colds-Practical Advice on Dosages and on the Time to Take These Nutrients/Botanicals in order to Prevent or Treat Common Colds. Evidence-Based Complementary and Alternative Medicine, 2018, 1-36.

Simonson, W. (2020). Vitamin C and coronavirus. Geriatric Nursing, 41(3), 331-332. https://doi.org/10.1016/j.gerinurse.2020.05.002

Singh, A. K., Majumdar, S., Singh, R., \& Misra, A. (2020). Role of corticosteroid in the management of COVID-19: A systemic review and a Clinician's perspective. Diabetes \& Metabolic Syndrome: Clinical Research \& Reviews, 14(5), 971-978.

Surani, S., \& Sharma, M. (2019). Revisiting the Role of Vitamin C in Sepsis. Is it a Forlorn Hope or is there Still Dearth of data? The Open Respiratory Medicine Journal, 13(1), 55-57

Thirumdas, R., Kothakota, A., Pandiselvam, R., Bahrami, A., \& Barba, F. J. (2021). Role of food nutrients and supplementation in fighting against viral infections and boosting immunity: A review. Trends in Food Science \& Technology, 110, 66-77.

Tolonen, M. (1996). Vitamins. In Vitamins and Minerals in Health and Nutrition (pp. 99-147). Elsevier.

Valavanidis, A., Vlachogianni, T., Fiotakis, K., \& Loridas, S. (2013). Pulmonary Oxidative Stress, Inflammation and Cancer: Respirable Particulate Matter, Fibrous Dusts and Ozone as Major Causes of Lung Carcinogenesis through Reactive Oxygen Species Mechanisms. International Journal of Environmental Research and Public Health, 10(9), 3886-3907.

Wang, Y., Lin, H., Lin, B., \& Lin, J. (2019). Effects of different ascorbic acid doses on the mortality of critically ill patients: A metaanalysis. Annals of Intensive Care, 9(1), 58.

What are the Best Food for Vitamin C? (n.d.). Retrieved from https://www.news-medical.net/health/Sources-of-Vitamin-C.aspx 